\title{
Interaction between poly(3-hydroxybutyrate) granule-associated proteins as revealed by two-hybrid analysis and identification of a new phasin in Ralstonia eutropha $\mathrm{H} 16$
}

\author{
Daniel Pfeiffer and Dieter Jendrossek
}

Correspondence

Dieter Jendrossek

dieter.jendrossek@imb.

uni-stuttgart.de

Received 25 May 2011

Revised 4 July 2011

Accepted 6 July 2011

\author{
Institut für Mikrobiologie, Universität Stuttgart, Allmandring 31, Stuttgart, Germany
}

\section{INTRODUCTION}

Ralstonia eutropha is the model organism for accumulation of poly(3-hydroxyalkanoates) (PHA) (Pohlmann et al., 2006; Pötter \& Steinbüchel, 2006; Steinbüchel \& Hein, 2001; Stubbe et al., 2005; Sudesh et al., 2000). At least 17 proteins have been described that are important for the biosynthesis, maintenance and intracellular utilization (mobilization) of poly(3-hydroxybutyrate) (PHB): four phasin proteins [PhaP1-PhaP4; phasins are PHB granuleassociated proteins (PGAPs) with putative structural functions] (Pieper-Fürst et al., 1994; Pötter et al., 2002, 2004, 2005; York et al., 2001a, b), seven intracellular PHB depolymerases (PhaZs) (Abe et al., 2005; Handrick et al., 2000; Saegusa et al., 2001; York et al., 2003), two 3-hydroxybutyrate oligomer hydrolases (PhaZb, PhaZc or PhaYs) (Kobayashi et al., 2003, 2005), a regulator protein,

Abbreviations: BACTH system, bacterial adenylate cyclase-based two-hybrid system; MU, Miller units; $\mathrm{nPHB}$, native PHB; PGAP, PHB granule-associated protein; PHA, poly(3-hydroxyalkanoates); PHB, poly(3-hydroxybutyrate).
PhaR (Pötter et al., 2002; York et al., 2002), and the three main PHB biosynthetic enzymes [ $\beta$-ketothiolase (PhaA), acetoacetyl-CoA reductase (PhaB1) and PHB synthase $(\mathrm{PhaC} 1)]$ of the phaCAB operon. Some of the 17 proteins mentioned above have been shown experimentally to be PHB granule-bound or are likely to be PHB granulebound. There may even be other as-yet-unidentified proteins involved in PHB metabolism and PHB granule formation. The $R$. eutropha genome has many isogenes encoding putative reductase proteins (e.g. phaB3) and thiolase proteins, as well as a second PHA synthase gene (phaC2) and proteins with phasin-like sequence motifs (Budde et al., 2010; Pohlmann et al., 2006). In vitro studies using isolated native $\mathrm{PHB}(\mathrm{nPHB})$ granules suggest that all activities that are necessary to synthesize PHB from acetyl$\mathrm{CoA}$ and to mobilize $\mathrm{PHB}$ are attached to isolated $\mathrm{nPHB}$ granules (Uchino et al., 2007). Reports for other PHAaccumulating organisms show that acyl-CoA synthetase (Acs1) is bound to the PHA granule surface in vivo in Pseudomonas putida (Ruth et al., 2008). These findings suggest that PHA granules are much more than simple 
storage tanks for carbon end energy; rather, they are highly organized supramolecular complexes for which we have proposed the designation 'carbonosome' to indicate an organelle-like function (Jendrossek, 2009).

While considerable knowledge of the number of different PGAPs has accumulated, little is known about the organization of these PGAPs on the PHA granule surface. In particular, it is not known whether these proteins are randomly organized on the $\mathrm{PHB}$ granule surface or whether there are specific protein-protein interactions between some of the PGAPs that result in an ordered surface structure. To address this question experimentally, we used a two-hybrid approach for identification of potentially interacting proteins. Two-hybrid assays were first described for yeasts (Fields \& Song, 1989), but bacterial counterparts of two-hybrid assays have been developed in recent years (e.g. Dove \& Hochschild, 2001, 2004; Wang et al. 2011). In this study we used the bacterial two-hybrid system described by Karimova et al. (1998). This method takes advantage of the reconstitution of adenylate cyclase activity in an adenylate cyclase-deficient Escherichia coli reporter strain (Karimova et al., 2000a, b). For this, two plasmids are used, each encoding one half of an adenylate cyclase (from Bordetella pertussis, named T18 and T25 fragments). Physical interactions between two test proteins that are fused to the T18 and T25 fragments result in the reconstitution of adenylate cyclase activity and in the formation of red colonies on MacConkey agar, or in growth and formation of blue colonies on X-Gal-containing mineral salts medium with lactose or maltose (Fig. 1).

Earlier investigations of the PHB synthase of R. eutropha in vitro (class I PHB synthase) have suggested that PHB synthase activity depends on homo-oligomerization of $\mathrm{PhaCl}_{\text {Reu }}$ subunits (Stubbe \& Tian, 2003; Stubbe et al., 2005; Wodzinska et al., 1996). In Bacillus megaterium, PHB synthase (class IV) consists of two different subunits $\left(\mathrm{PhaC}_{B m e g}\right.$ and $\left.\mathrm{PhaR}_{\text {Bmeg }}\right)$ (McCool \& Cannon, 1999, 2001; Pötter \& Steinbüchel, 2006; Rehm, 2003, 2006), and only the heterodimer PhaC-PhaR has PHB synthase activity. We first tested the versatility of the adenylate cyclase twohybrid system by confirmation of homo-oligomerization of R. eutropha $\mathrm{PhaC1}$ subunits and by hetero-oligomerization of $B$. megaterium phaC $C_{B m e g}$ and $\mathrm{phaR_{Bmeg }}$ PHB synthase subunits before the system was used to identify new interactions.

\section{METHODS}

Bacterial strains and plasmids. Bacterial strains and plasmids used in this study are shown in Table 1. E. coli strain JM109 was used in cloning experiments, and was routinely grown on Luria broth (LB) supplemented with the appropriate antibiotics at $37^{\circ} \mathrm{C}$. R. eutropha strains were routinely grown on nutrient broth (NB) medium at $30{ }^{\circ} \mathrm{C}$. Sodium gluconate $(0.2 \%, \mathrm{w} / \mathrm{v})$ was added to promote PHB accumulation.

Two-hybrid assays were performed with E. coli BTH101 harbouring the pUT18C and pKT25 plasmid combination of interest on LB agar containing $100 \mu \mathrm{g}$ ampicillin $\mathrm{ml}^{-1}, 50 \mu \mathrm{g}$ kanamycin $\mathrm{ml}^{-1}, 0.5 \mathrm{mM}$ IPTG and $40 \mu \mathrm{g} \mathrm{X}-\mathrm{Gal} \mathrm{ml} \mathrm{m}^{-1}$ at $30^{\circ} \mathrm{C}$ or room temperature. Alternatively, MacConkey agar containing $1 \%(\mathrm{w} / \mathrm{v})$ lactose, $100 \mu \mathrm{g}$ ampicillin $\mathrm{ml}^{-1}, 50 \mu \mathrm{g}$ kanamycin $\mathrm{ml}^{-1}$ and $0.5 \mathrm{mM}$ IPTG, or M63 mineral salts agar containing $50 \mu \mathrm{g}$ ampicillin $\mathrm{ml}^{-1}, 25 \mu \mathrm{g}$ kanamycin $\mathrm{ml}^{-1}, 0.5 \mathrm{mM}$ IPTG, $40 \mu \mathrm{g} \mathrm{X}-\mathrm{Gal} \mathrm{ml}^{-1}$ and $0.2 \%$ (w/v) maltose as sole carbon source was also used. Depending on the degree of protein-protein interaction, the development of colonies and of a blue colour took $2-8$ days at $30{ }^{\circ} \mathrm{C}$.

Two-hybrid assay. For construction of pUT18C and pKT25 variant plasmids, the gene of interest was PCR-amplified from isolated chromosomal DNA of $R$. eutropha $\mathrm{H} 16$ and B. megaterium, respectively, using a proof-reading DNA polymerase. The primers used for PCR are summarized in Table 2. The primers additionally encoded two restriction endonuclease sites suitable for cloning in pUT18C and pKT25 vectors. The PCR products were cut with the respective endonucleases, purified, and cloned into pUT18C and pKT25. The DNA sequences of the inserts were determined. Only clones encoding correct amino acid sequences were used for twohybrid assays. The two-hybrid assay was principally performed in both combinations, meaning that each gene was cloned into both pUT18C and pKT25, and that both combinations of each test pair were investigated. Only if both combinations gave signals that were significantly more intense than controls (pUT18C fusion with pKT25 and pKT25 fusion with pUT18C) was the outcome regarded as positive.

Two-hybrid screening of a genomic library of $\boldsymbol{R}$. eutropha. A genomic library of $R$. eutropha $\mathrm{H} 16$ fused to the $3^{\prime}$ end of the gene for the Bordetella pertussis adenylate cyclase T18 domain was constructed. Isolated genomic DNA of $R$. eutropha $\mathrm{H} 16$ was partially digested with DNase I in the presence of $50 \mathrm{mM}$ Tris/ $\mathrm{HCl}, \mathrm{pH} 7.5$, supplemented with $1 \mathrm{mM} \mathrm{MnCl}_{2}$. The resulting DNA fragments, ranging from 400 to $2000 \mathrm{bp}$, were isolated by agarose gel electrophoresis, end-repaired by Klenow DNA polymerase and subsequently ligated with BstXI adaptors (annealed oligonucleotides BstXC and BstXD). Remaining adaptor molecules and adaptor dimers were removed by multiple rounds of agarose gel electrophoresis and spin-column purification. Subsequently, the DNA fragments were ligated to a BstXI-digested pUT18BC-Kan1 vector and transformed into electrocompetent E. coli 10B cells (TFB Electro 10B, Transformation Biosciences). In total, approximately $2.6 \times 10^{6}$ clones were obtained. Amplification of inserted DNA fragments from 76 randomly chosen clones by colony PCR confirmed the presence of inserts ranging from 300 to $1700 \mathrm{bp}$. Of 76 clones, 72 harboured chromosomal DNA inserts, and only four clones had an adaptor dimer as insert. All colonies of the genomic library were resuspended in buffer, and plasmid DNA was isolated from the resulting pool using a NucleoBond AX 500 cartridge (Qiagen). This plasmid library was used for two-hybrid screening experiments. Fig. 1 shows the procedure schematically.

The bait construct (pKT25-phaP2) was transformed into the adenylate cyclase-deficient reporter strain E. coli BTH101, and electrocompetent cells were prepared from a representative transformant. About $100 \mathrm{ng}$ of the genomic library in pUT18BC-Kan1 was used for transformation of $40 \mu \mathrm{l}$ of electrocompetent bait cells (BioRad Gene Pulser II System, $0.2 \mathrm{~cm}$ cuvette, $25 \mu \mathrm{F}, 2.5 \mathrm{kV}, 200 \Omega$ ). A $960 \mu \mathrm{l}$ volume of SOB medium ( $5 \mathrm{~g}$ yeast extract $\mathrm{l}^{-1}, 20 \mathrm{~g}$ tryptone $1^{-1}, 0.6 \mathrm{~g} \mathrm{NaCl} \mathrm{l}^{-1}, 0.2 \mathrm{~g} \mathrm{KCl} \mathrm{l}^{-1}, 10 \mathrm{mM} \mathrm{MgSO}_{4}, 10 \mathrm{mM} \mathrm{MgCl}$ ) was added and cells were incubated at $37^{\circ} \mathrm{C}$ for $90 \mathrm{~min}$. Cells were washed three times with M63 mineral salts medium, and $2 \times 10^{8}$ to $6 \times 10^{8}$ c.f.u. per experiment (approx. $10^{7}$ transformants per plate) was plated on M63 mineral salts maltose $(0.2 \%$, w/v) agar supplemented with X-Gal $\left(40 \mu \mathrm{g} \mathrm{ml}^{-1}\right), 0.5 \mathrm{mM}$ IPTG, ampicillin $\left(50 \mu \mathrm{g} \mathrm{ml}^{-1}\right)$ and kanamycin sulfate $\left(25 \mu \mathrm{g} \mathrm{ml}^{-1}\right)$. Blue-coloured $\mathrm{Cya}^{+}$colonies appeared after $3-8$ days of incubation at $30{ }^{\circ} \mathrm{C}$. 
Table 1. Strains and plasmids used in this study

\begin{tabular}{|c|c|c|}
\hline Strain or plasmid & Relevant characteristics or features ${ }^{\star}$ & Reference or source \\
\hline \multicolumn{3}{|l|}{ Strains } \\
\hline E. coli JM109 & Cloning strain & \\
\hline E. coli BTH101 & $\begin{array}{l}\text { Cya-BACTH expression strain; } \mathrm{F}^{-} \text {cya-99 araD139 galE15 } \\
\text { galK16 rpsL1 }\left(\mathrm{Str}^{\mathrm{r}}\right) \text { hsdR2 mcrA1 mcrB1 }\end{array}$ & Karimova et al. (2005) \\
\hline E. coli $\mathrm{S} 17-1$ & Conjugation strain & Simon et al. (1983) \\
\hline E. coli $10 \mathrm{~B}$ & Transformation strain & Transformation Biosciences \\
\hline B. megaterium & PHB synthase type IV & DSMZ 168 \\
\hline R. eutropha $\mathrm{H} 16$ & PHB synthase type I & DSMZ 428 \\
\hline R. eutropha HF39 & $\begin{array}{l}\text { Streptomycin-resistant mutant of } R . \text { eutropha H16 used for } \\
\text { conjugation }\end{array}$ & Srivastava et al. (1982) \\
\hline R. eutropha H16 $\Delta$ phaP5 & Chromosomal deletion of $h 16 \_b 1934$ & This study \\
\hline R. eutropha HF39 $\Delta$ phaP5 & Chromosomal deletion of h16_b1934 & This study \\
\hline \multicolumn{3}{|l|}{ Plasmids } \\
\hline pJM9238 & $\begin{array}{l}\text { Runaway replication vector harbouring the } R \text {. eutropha } \\
\text { phaCAB operon, } \mathrm{Cm}^{\mathrm{r}}\end{array}$ & Kidwell et al. (1995) \\
\hline pEYFP-C1 & Source of eyfp-cl & Clontech \\
\hline pUT18C & $\begin{array}{l}\text { BACTH vector designed to express a given polypeptide } \\
\text { fused in-frame at its N-terminal end with the T18 fragment; } \\
\text { ColE1 ori; } \mathrm{Amp}^{\mathrm{r}}\end{array}$ & Karimova et al. (2001) \\
\hline pUT18BC-Kan1 & pUT18C with two BstXI sites & D. Ladant \\
\hline pKT25 & $\begin{array}{l}\text { BACTH vector designed to express a given polypeptide } \\
\text { fused in-frame at its } \mathrm{N} \text {-terminal end with the T25 } \\
\text { fragment; p15 ori; } \mathrm{Km}^{\mathrm{r}}\end{array}$ & Karimova et al. (2001) \\
\hline pUT18C-zip, pKT25-zip & $\begin{array}{l}\text { Derivatives of pUT18C and pKT25 with a } 114 \text { bp DNA } \\
\text { fragment encoding a leucine zipper (positive control } \\
\text { for two-hybrid assays) }\end{array}$ & Karimova et al. (2001) \\
\hline pUT18C-phaR $R_{\text {Bmeg }}$ pKT25-phaC $C_{\text {Bmeg }}$ & $\begin{array}{l}\text { B. megaterium phaR and phaC cloned into pUT18C } \\
\text { and pKT25 via PstI and KpnI restriction sites }\end{array}$ & This study \\
\hline pUT18C-phaC1 $1_{R e w}$, pKT25-phaC1 $1_{R e u}$ & $\begin{array}{l}\text { R. eutropha phaC1 cloned into pUT18C and pKT25 via } \\
\text { XbaI and SmaI restriction sites }\end{array}$ & This study \\
\hline $\begin{array}{l}\text { pUT18C/pKT25-phaP1, -phaP2, } \\
\text {-phaP3, -phaP4, -phaR, -phaA, } \\
\text {-phaB1, -phaZ1, -phaP5 }\end{array}$ & $\begin{array}{l}\text { R. eutropha pha ORFs cloned into pUT18C and pKT } 25 \text { via } \\
\text { XbaI and KpnI restriction sites }\end{array}$ & This study \\
\hline pBBR1MCS-2 & Broad-host-range vector, $\mathrm{Km}^{\mathrm{r}}$ & Kovach et al. (1995) \\
\hline pBBR1MCS-2- $\mathrm{P}_{\text {phac }}$ & $\begin{array}{l}\text { pBBR1MCS- } 2 \text { containing a PCR fragment with the wild-type } \\
\text { promoter and Shine-Dalgarno sequence of phaCAB }\end{array}$ & This study \\
\hline pBBR1MCS-2-P ${ }_{p h a C^{-}}$eyfp-cl & $\begin{array}{l}\text { Universal vector for construction of fusions C-terminal } \\
\text { to eYfp under the control of the } p h a C A B \text { promoter }\end{array}$ & This study \\
\hline $\begin{array}{l}\text { pBBR1MCS-2-P } \mathrm{P}_{\text {phac }} \text { eyfp-phaP2, } \\
\text {-phaP4, -phaP5 }\end{array}$ & $\begin{array}{l}\text { R. eutropha } \mathrm{H} 16 \text { phaP2, phaP4 or phaP5 (h16_b1934) } \\
\text { cloned in-frame to eyfp via the XhoI and BamHI restriction } \\
\text { sites of pBBR1MCS-2- } \mathrm{P}_{\text {phac }} \text { eyfp-cl }\end{array}$ & This study \\
\hline pLO3 & Deletion vector; $\mathrm{Tc}^{\mathrm{r}}$ & Lenz \& Friedrich (1998) \\
\hline pLO3- $\Delta p h a P 5$ & $\begin{array}{l}\text { Deletion vector for } h 16 \_b 1934 ; 500 \text { bp upstream and } \\
\text { downstream of the gene were connected via overlap-PCR } \\
\text { and cloned between the SacI and XbaI restriction sites of pLO3 }\end{array}$ & This study \\
\hline
\end{tabular}

${ }^{*}$ Abbreviations: $\mathrm{Amp}^{\mathrm{r}}$, ampicillin-resistant; $\mathrm{Cm}^{\mathrm{r}}$, chloramphenicol-resistant; $\mathrm{Km}^{\mathrm{r}}$, kanamycin-resistant; Str ${ }^{\mathrm{r}}$, streptomycin-resistant; $\mathrm{Tc}^{\mathrm{r}}$, tetracycline-resistant.

Selected $\mathrm{Cya}^{+}$colonies were purified on M63-maltose medium and characterized by DNA sequencing of the inserts. Transformation efficiency was determined by plating aliquots on LB-ampicillinkanamycin agar.

Construction of fusion proteins with eYfp and of chromosomal knockouts. A universal vector based on the broad-host-range plasmid pBBR1MCS-2 (Kovach et al., 1995), which allows expression of proteins fused to the $\mathrm{C}$ terminus of eYfp under the control of the constitutive phaCAB promoter, was constructed. First, a 466 bp PCRgenerated DNA fragment that included the promoter and ShineDalgarno (SD) sequence of the phaCAB operon was cut with KpnI and cloned between the KpnI and SmaI restriction sites of pBBR1MCS-2. The resulting plasmid, pBBR1MCS-2-P phac, was cut 
Table 2. Oligonucleotides used in this study

Restriction sites are underlined. Start and stop codons are shown in bold type.

\begin{tabular}{|c|c|}
\hline Oligonucleotide & Sequence $\left(5^{\prime}-3^{\prime}\right)$ \\
\hline \multicolumn{2}{|l|}{ Two-hybrid analysis } \\
\hline B.m._phaR_C_forward_PstI & AACTGCAGTTTGGAACAGCAAAAAGTATTTGATCC \\
\hline B.m._phaR_C_reverse_KpnI & GGGGTACCTACTTGCGAGCCGGCTG \\
\hline B.m._phaC_C_forward_PstI & AACTGCAGTCGTGGCAATTCCTTACGTG \\
\hline B.m._phaC_C_reverse_KpnI & GGGGTACCTATTTAGAGCGTTTTTCTAGCCAATCG \\
\hline R.e._phaC1_C_forward_XbaI & GCTCTAGACATGGCGACCGGCAAAGG \\
\hline R.e._phaC1_C_reverse_SmaI & TCCCCCGGGCGTCATGCCTTGGCTTTGACG \\
\hline R.e._phaP1_C_forward_XbaI & GCTCTAGAAATGATCCTCACCCCGGAAC \\
\hline R.e._phaP1_C_reverse_KpnI & GGGGTACCTCAGGCAGCCGTCGTC \\
\hline R.e._phaP2_C_forward_XbaI & GCTCTAGAGATGACTCAGTGGACAGCAG \\
\hline R.e._phaP2_C_reverse_KpnI & GGGGTACCCTACTTTGCAGCTGCCGG \\
\hline R.e._phaP3_C_forward_XbaI & GCTCTAGACATGTCCCCTTTTATGCCCG \\
\hline R.e._phaP3_C_reverse_KpnI & GGGGTACCTTATTGCTTGGAAGCGCGG \\
\hline R.e._phaP4_C_forward_XbaI & GCTCTAGAGATGACTCAGTGGTCCCCC \\
\hline R.e._phaP4_C_reverse_KpnI & GGGGTACCTTAATTTGCAGCTGCCTTTGAGG \\
\hline R.e._phaA_C_forward_XbaI & GCTCTAGAAATGACTGACGTTGTCATCGTATC \\
\hline R.e._phaA_C_reverse_KpnI & GGGGTACCTTATTTGCGCTCGACTGCC \\
\hline R.e._phaB1_C_forward_XbaI & GCTCTAGACATGACTCAGCGCATTGCG \\
\hline R.e._phaB1_C_reverse_KpnI & GGGGTACCTCAGCCCATATGCAGGCC \\
\hline R.e._phaR_C_forward_XbaI & GCTCTAGAGATGGCCACGACCAAAAAAGG \\
\hline R.e._phaR_C_reverse_KpnI & 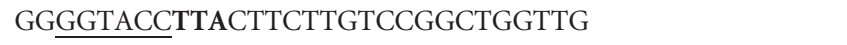 \\
\hline R.e._phaZ1_C_forward_XbaI & GCTCTAGACATGCTCTACCAATTGCATGAGTTC \\
\hline R.e._phaZ1_C_reverse_KpnI & GGGGTACCTTACCTGGTGGCCGAGG \\
\hline R.e._H16_B1934_C_forward_XbaI & GCTCTAGACATGGCCACGCCTCCC \\
\hline R.e._H16_B1934_C_reverse_KpnI & GGGGTACCCTAGCCCTTGGATTTCGGCTTG \\
\hline BstXC & p-CTGGTTCCGCGGGC \\
\hline BstXD & p-GCCCGCGGAACCAGCTCC \\
\hline \multicolumn{2}{|l|}{ eyfp fusions } \\
\hline phaC-promoter_forward_KpnI & GGGGTACCCAAAAATTCATCCTTCTCGCCTATGC \\
\hline phaC-promoter_reverse_NdeI & GGGAATTCCATATGTTGATTGTCTCTCTGCCGTCAC \\
\hline EYFP-C1_forward_NdeI & GGGAATTCCATATGGTGAGCAAGGGCGAGG \\
\hline EYFP-C1_reverse_SpeI & GGACTAGTTGATCAGTTATCTAGATCCGGTGGATCC \\
\hline R.e._phaP2_C_forward_XhoI & CCGCTCGAGGCATGACTCAGTGGACAGCAG \\
\hline R.e._phaP2_C_reverse_BamHI & CGGGATCCCTACTTTGCAGCTGCCGG \\
\hline R.e._phaP4_C_forward_XhoI & CCGCTCGAGGCATGACTCAGTGGTCCCCC \\
\hline R.e._phaP4_C_reverse_BamHI & CGGGATCCTTAATTTGCAGCTGCCTTTGAGG \\
\hline R.e._H16_B1934_C_forward_XhoI & CCGCTCGAGGCATGGCCACGCCTCCC \\
\hline R.e._H16_B1934_C_reverse_BamHI & CGGGATCCCTAGCCCTTGGATTTCGGCTTG \\
\hline \multicolumn{2}{|l|}{ phaP5 deletion } \\
\hline B1934upstreamF & CGATCAGAGCTCCACTGCGCGCCACCGCCG \\
\hline B1934upstreamR & GCCGTTAATTAAGCCGGCTGGGTCTCCTTCTGGAAGGACTGGC \\
\hline B1934downstreamF & CGGCTTAATTAACGGCCCCAGGCCACCGCTAGCGCTGC \\
\hline B1934downstreamR & GCTCTAGACGCGGCCACCGACCCGTCC \\
\hline
\end{tabular}

with NdeI and SpeI, and ligated with a DNA fragment encoding the polylinker and eyfp-coding sequence of pEYFP-C1, yielding

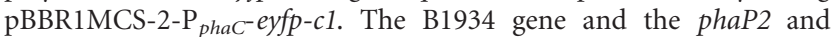
phaP4 genes were each cloned in-frame to the eyfp gene between the

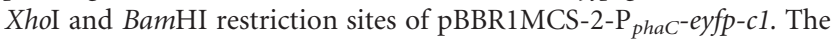
resulting plasmids were conjugatively transferred from $E$. coli S17-1 to $R$. eutropha HF39. A precise chromosomal deletion of B1934 ( $\triangle$ phaP5) was constructed in R. eutropha H16 and HF39 using the sacB-sucrose selection method and pLO3 as deletion vector, as described elsewhere (Lenz \& Friedrich, 1998). Fluorescence microscopy analysis was done as described previously (Jendrossek, 2005; Jendrossek et al., 2007).
Determination of $\boldsymbol{\beta}$-galactosidase activity. All assays were performed in triplicate and the means were calculated. The strain of interest was grown in $2.5 \mathrm{ml} \mathrm{LB}$ medium supplemented with $100 \mu \mathrm{g}$ ampicillin $\mathrm{ml}^{-1}, 50 \mu \mathrm{g}$ kanamycin $\mathrm{ml}^{-1}$ and $0.5 \mathrm{mM}$ IPTG at $30{ }^{\circ} \mathrm{C}$ and 150 r.p.m. for $16 \mathrm{~h}$. The $\beta$-galactosidase assay was performed according to the protocol described by the manufacturer (Euromedex). Alternatively, cells were grown in 96-deep-well plates ( $1 \mathrm{ml}$ volume per well). A $100 \mu \mathrm{l}$ volume of $1: 5$ diluted cells was mixed with $900 \mu \mathrm{l} \mathrm{Z}$ buffer $\left(10.7 \mathrm{~g} \mathrm{Na}_{2} \mathrm{HPO}_{4} \cdot 2 \mathrm{H}_{2} \mathrm{O} \mathrm{l}^{-1}\right.$, $5.5 \mathrm{~g}$ $\mathrm{NaH}_{2} \mathrm{PO}_{4} 1^{-1}, 0.75 \mathrm{~g} \mathrm{KCl} \mathrm{l}^{-1}, 0.246 \mathrm{~g} \mathrm{MgSO}_{4} \cdot 7 \mathrm{H}_{2} \mathrm{O} \mathrm{l}{ }^{-1}, 2.7 \mathrm{ml}$ $\beta$-mercaptoethanol $\left.1^{-1}, \mathrm{pH} 7\right)$ before $20 \mu \mathrm{l}$ of $0.1 \%(\mathrm{w} / \mathrm{v})$ SDS and $20 \mu \mathrm{l}$ toluene were added for permeabilization. Toluene was 
(a)

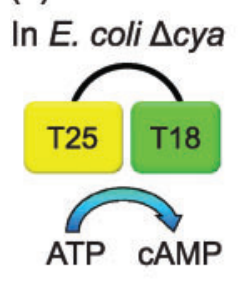

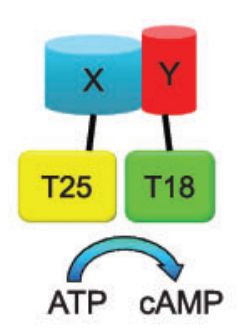

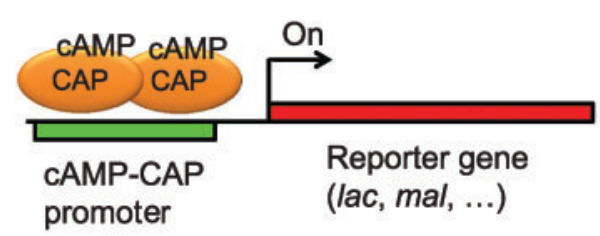

(b)
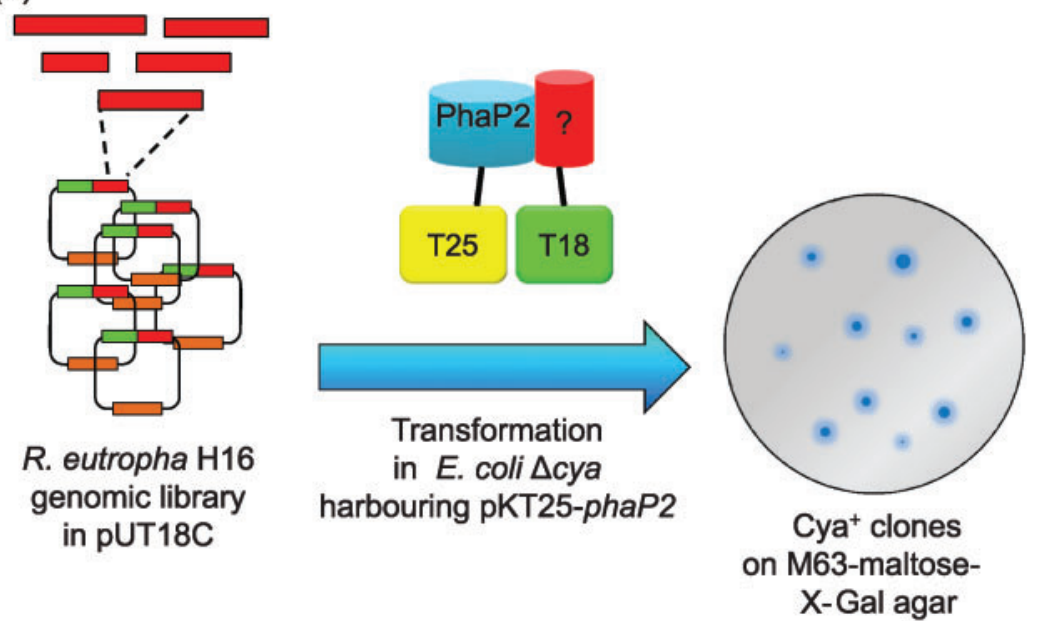

Fig. 1. Principles of the adenylate cyclasebased two-hybrid approach (a), and screening of a genomic library for interactions with a bait gene of interest (b). evaporated by shaking at 150 r.p.m. and $37^{\circ} \mathrm{C}$ for $40 \mathrm{~min}$. A $30 \mu \mathrm{l}$ volume of ONPG solution $\left(4 \mathrm{mg} \mathrm{ml}{ }^{-1}\right.$ in $\mathrm{Z}$ buffer without $\beta$ mercaptoethanol) was added to $150 \mu \mathrm{l}$ of permeabilized cells, and activity measurement was carried out by recording $A_{420}$ for $40 \mathrm{~min}$ using a microplate reader [all steps with prewarmed $\left(28{ }^{\circ} \mathrm{C}\right)$ solutions]. $\beta$-Galactosidase activity in Miller units (MU) was then calculated (Thibodeau et al., 2004). For conversion of microplate reader $A_{600}$ and $A_{420}$ values into standard photometer values, correction factors were determined using serial dilutions of cells and an $o$-nitrophenyl (ONP) solution. One unit of $\beta$-galactosidase activity per milligram corresponds to $1.5 \mathrm{MU}$.

\section{RESULTS}

The ability of the PHB synthase of $R$. eutropha $\left(\mathrm{PhaCl}_{\text {Reu }}\right)$ and those of $B$. megaterium $\left(\mathrm{PhaC}_{B \text { meg }}, \mathrm{PhaR}_{\text {Bmeg }}\right)$ to form $\mathrm{PhaCl}_{\text {Reu }}$ homo-oligomers and $\mathrm{PhaC}_{B m e g}-\mathrm{PhaR}_{\text {Bmeg }}$ hetero-oligomers in vivo was tested by two-hybrid assay. When the empty plasmids (pUT18C + pKT25), or one of the empty plasmids in combination with the respective pUT18C or pKT25 hybrid plasmid carrying one of the PHB synthase gene fusions, were tested, the streaks generally were white on IPTG-X-Gal LB medium, indicating that no significant adenylate cyclase activity was restored (negative controls, Fig. 2a). In contrast, the strain with the positive control (leucine zipper) became blue within $30 \mathrm{~h}$ of incubation at $30{ }^{\circ} \mathrm{C}$. When the plasmid combinations [(pUT18C-phaC1 $1_{\text {Reu }}+$ pKT25-phaC1 $1_{\text {Reu }}$ ) or (pUT18C-phaR Bmeg $_{\text {B }}$ + pKT25-pha $\left.\left.C_{B m e g}\right)\right]$ were tested the colonies of the three strains turned blue within 2-3 days of incubation (Fig. 2a). Apparently, the $R$. eutropha PHB synthase $\mathrm{PhaCl}_{\text {Reu }}$ forms homo-oligomers in vivo, resulting in reconstitution of adenylate cyclase activity. Similarly, the fusions with $\mathrm{PhaC}_{\text {Bmeg }}$ and $\mathrm{PhaR}_{\text {Bmeg }}$ associated to hetero-dimers, as indicated by formation of blue colonies. The same principal results were obtained when the experiments were repeated in a PHB-producing E. coli background (pJM9238) (data not shown). Apparently, the presence of PHB did not significantly influence the two-hybrid assay. However, colour development was less intense, probably because of the accumulation of (white) PHB. Determination of specific $\beta$-galactosidase activities after growth of two-hybrid strains in liquid cultures (Fig. 2b) showed that the activities for the combinations of the $R$. eutropha phaC1 gene were twofold [100 U (mg cell dry 

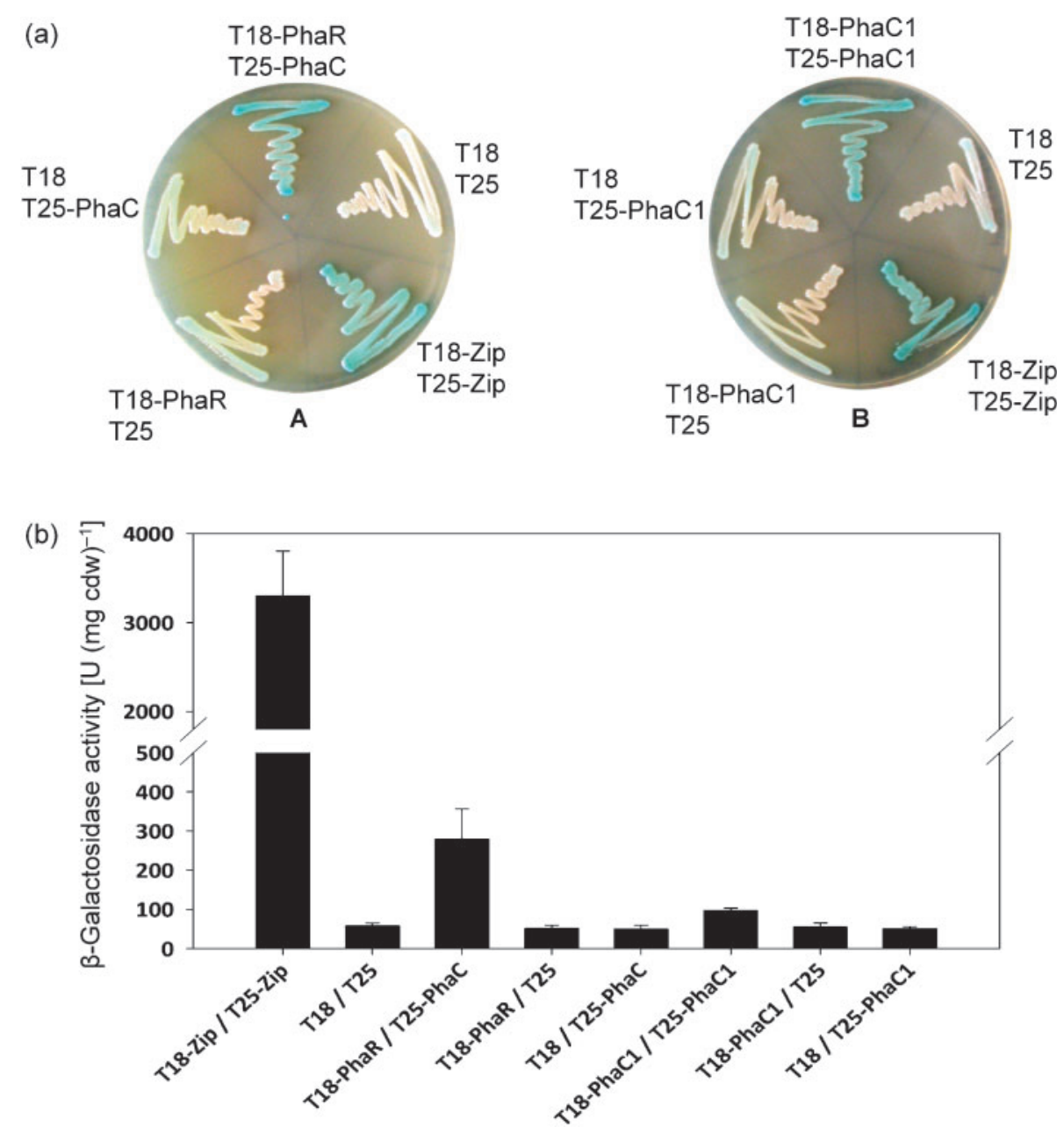

Fig. 2. (a) BACTH analysis of PHB synthase subunits. Co-transformants of $E$. coli BTH101 expressing T18 and T25 fusions of (A) B. megaterium phaR $R_{B m e g}$ and $p h a C_{B m e g}$, and (B) R. eutropha phaC1 $1_{\text {Reu }}$ and control strains, were grown on LB-X-Gal medium at $30{ }^{\circ} \mathrm{C}$ for 2 days. Zip, leucine zipper (positive control). (b) $\beta$-Galactosidase activity assay. The efficiency of functional complementation was quantified in suspensions of SDS/toluene-treated E. coli BTH101 cells harbouring the indicated constructs. Values shown are the mean results from three independent cultures; error bars, SD. cdw, cell dry weight.

weight $)^{-1}$ ] and those for the $B$. megaterium PHB synthase

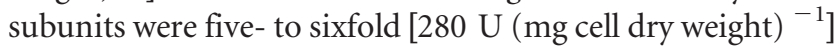
higher in comparison with the negative controls $[\sim 50 \mathrm{U}(\mathrm{mg}$ cell dry weight $)^{-1}$ ]. Several repetitions of the experiments using different growth temperatures or different growth times always led to similar results, i.e. the specific activities were between 40 and $70 \mathrm{U}$ (mg cell dry weight $)^{-1}$ for all negative controls; the values for the $\mathrm{PhaC} 1_{\text {Reu }}$ homooligomerization experiment were between 80 and $140 \mathrm{U}$ (mg cell dry weight $)^{-1}$ and those for the B. megaterium $\mathrm{PHB}$ synthase $\mathrm{PhaC}$ and $\mathrm{PhaR}$ fusions were between 140 and $280 \mathrm{U}$ (mg cell dry weight) ${ }^{-1}$. In conclusion, the adenylate cyclase-based two-hybrid system was able to detect proteinprotein interactions in vivo.

Next, we investigated the interaction between different known 'PHB players', and the following genes were
PCR-amplified and each was fused to the pUT18C and pKT25 vectors: the phasin genes phaP1, phaP2, phaP3 and phaP4; the intracellular PHB depolymerase gene phaZ1; the thiolase and reductase genes phaA and phaB1 of the PHB biosynthetic operon; and the regulatory gene phaR (Table 1). Please note that PhaR of $R$. eutropha (regulator) is not related to PhaR of B. megaterium (PHA synthase subunit). Each of the constructs was transformed in combination with the corresponding empty pendant vector (control) and in all possible permutations into the adenylate cyclasedeficient reporter strain E. coli BTH101. An agar-based two-hybrid assay was performed with all 101 individual $E$. coli clones using MacConkey agar and M63-maltose medium at $30{ }^{\circ} \mathrm{C}$. Overall, the two indicator media gave similar results (Fig. 3a, b). The M63-maltose medium (Fig. 3b) was more sensitive than MacConkey agar (Fig. 3a), as growth of the strains on M63-maltose agar depends on 
(a)

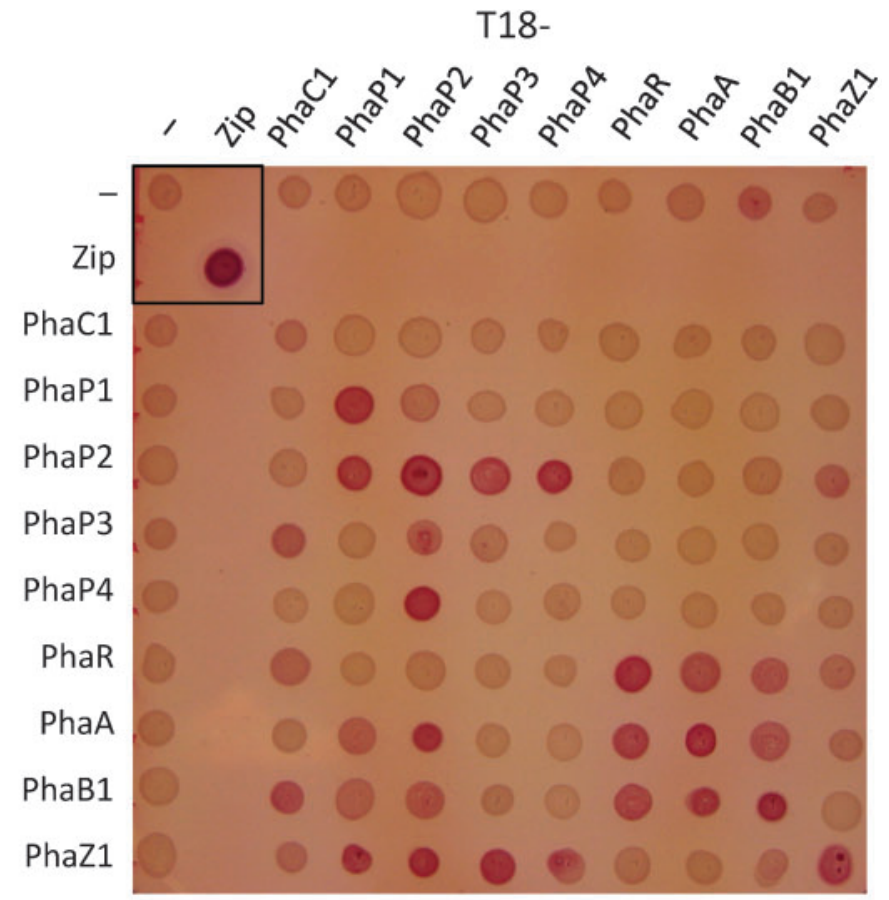

(b)

T18-

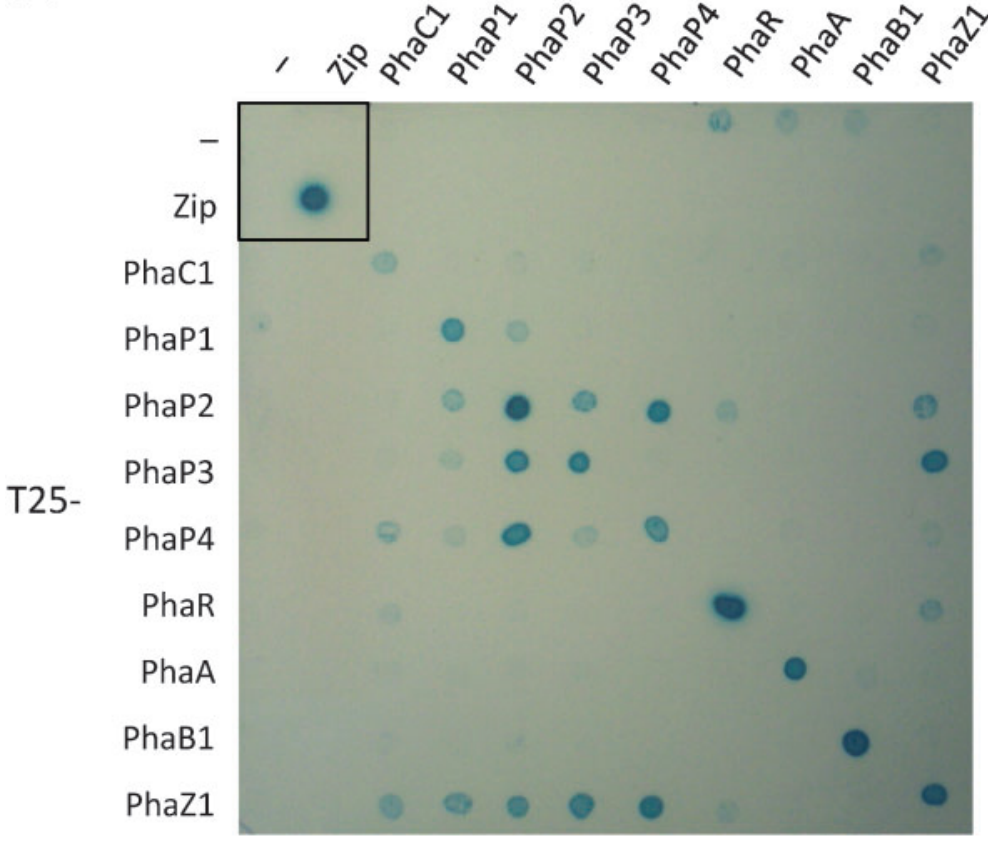

Fig. 3. BACTH analysis of proteins involved in PHB metabolism of $R$. eutropha. Cotransformants of $E$. coli BTH101 expressing the indicated T18 and T25 fusions were spotted on MacConkey agar (a) or M63maltose-mineral salts agar (b), and plates were incubated for 1.5 days at $30{ }^{\circ} \mathrm{C}$. -, Empty vector.

functional interactions of T18 and T25 fragments, while on MacConkey agar all strains can grow and the degree of protein interaction is indicated by (red) colour development only.

All negative controls in which the pKT25 bait constructs were tested in combination with the empty pUT18C vector and most pUT18C bait constructs with empty pKT25 resulted in no significant growth, similar to the strain with empty pKT25 or pUT18C plasmids (left lane of Fig. 3b). The control strains with the pUT18C-phaR, pUT18C-phaA and pUT18C-phaB1 constructs together with empty pKT25 showed weak growth and weak blue colour development, indicating minor background activity. The reverse experiments, i.e. the pKT25-phaR, pKT25-phaA and pKT25-phaB1 constructs plus empty pUT18C, did not show a positive reaction. Therefore, we considered only those assays as positive which showed growth and colour development in both plasmid combinations. 


\section{Homo-oligomerization}

All clones in which the same gene was fused to the T18 and T25 fragments were able to develop blue colonies (diagonals in Fig. 3). The strongest growth was obtained for clones harbouring PhaP2 or PhaR constructs. Apparently, the respective gene products are able to form oligomers in vivo.

\section{Interactions between different PGAPs}

(i) Phasins. All clones in which combinations of different phasin genes were tested for interaction gave more or less intense positive results. In particular, two-hybrid assays in which phaP2 was combined with any of the other three phasin genes resulted in strong growth and colour development. The PhaP2-PhaP4 interaction was notably strong, comparable with the positive control (leucine zipper). Apparently, phasins not only are able to form homo-oligomers but also can associate with each other and can form hetero-oligomers. Phasins also showed weak interactions with the intracellular PHB depolymerase PhaZ1.

(ii) PHB depolymerase PhaZ1. When E. coli clones harbouring the phaZ1 gene were assayed for their interaction potential with other Pha proteins, a weak signal was found with phasins, in particular with PhaP2 and PhaP3. A weak two-hybrid reaction near the detection limit was also found for PhaZ1 with the PHB synthase $\mathrm{PhaC} 1$ and with the regulator PhaR.

(iii) PHB synthase PhaC1. PhaC1 showed no interaction with any of the other tested gene products, except for a poor degree of homo-oligomerization and a weak reaction with PhaZ1.

(iv) Regulator PhaR. PhaR gave a very strong result in the homo-oligomerization experiment that was comparable with the positive control (leucine zipper), and a weak reaction near the detection limit with PhaZ1.

(v) PhaA and PhaB. Clones harbouring phaA or phaB1 fusions gave no growth or colour development on maltose agar in any of the tested combinations, except for homooligomerization.

\section{Screening for proteins capable of interaction with PhaP2}

The results described above indicated that some $\mathrm{PHB}$ granule-associated proteins are able to interact in vivo with each other. In particular, phasin PhaP2 revealed the highest degree of interaction with other PHB granule-associated proteins. This finding prompted us to investigate whether PhaP2 can interact with other proteins that have not yet been identified as PGAPs. The pKT25-phaP2 construct was used as bait to screen a $R$. eutropha H16 genomic library fused to pUT18C (see Methods and Fig. 1) to address this question. Several dozen blue-coloured clones developed within 4-6 days at $30{ }^{\circ} \mathrm{C}$, out of which 53 were isolated and sequenced. Interestingly, 24 clones that revealed the strongest growth and colour development on M63-maltose agar all contained parts of the coding sequence of the B1934 gene fused in-frame to the adenylate cyclase T18 fragment. The B1934 gene product is annotated as a hypothetical protein in the database and has a 'phasin protein' motif. The other sequenced clones that showed less intense growth on M63-maltose agar harboured parts of different genes, such as putative chemotaxis proteins (B0232, B2044), hypothetical transcriptional regulators (B0535, B1446, B1787), putative acyl-CoA dehydrogenases (A1530, B0703), and several other hypothetical proteins. The frequent identification of the B1934 gene and the phasin protein motif in the deduced amino acid sequences suggested that B1934 could encode a novel PGAP. The complete coding sequence ( $429 \mathrm{bp}$, corresponding to a polypeptide of $15.7 \mathrm{kDa}$ ) was fused to the T25 and T18 fragments, and the two-hybrid assay was repeated with all nine other pha genes. The interaction of the B1934 gene product with $\mathrm{PhaP} 2$ was confirmed in both plasmid combinations (Fig. 4a). Interestingly, the B1934 gene product also interacted with the other phasins, with PhaR and with PhaZ1, and showed high homo-oligomerization potential. No interaction was detected with the PHB synthase PhaCl and with PhaA or PhaB1. These results were confirmed by quantitative determination of $\beta$-galactosidase activities after growth of the respective $E$. coli clones (Fig. 4b): the highest values were obtained for the homo-oligomerization (2100 MU), for interaction with PhaP2 (1150 MU), PhaR (530 MU), PHB depolymerase PhaZ1 (360 MU) and the other phasins (100-250 MU). The values for the controls (T18-PhaP5 with T25 and T25PhaP5 with T18) amounted to 55 and $40 \mathrm{MU}$, respectively.

\section{Subcellular localization of the B1934 gene product}

Our results indicate that the B1934 gene product is probably a new 'PHB player', and presumably is attached to the PHB granule surface. To find evidence for this assumption, an eyfp-b1934 fusion was constructed in pBBR1MCS-2 (under the control of the constitutive phaC promoter). The resulting construct, pBBR1MCS$2:: \mathrm{P}_{\text {phac }}$ eyfp- $b 1934$, was conjugatively transferred to $R$. eutropha and investigated for PHB granule formation and localization of fusion proteins. PHB-free cells of $R$. eutropha transconjugants harbouring the constructs with and without the fusion were transferred to medium permissive for $\mathrm{PHB}$ accumulation $\left(30^{\circ} \mathrm{C}\right)$, and samples were analysed by fluorescence microscopy. As shown in Fig. 5(a), free eYfp (control) was distributed in the cytoplasm independently of the presence or absence of PHB granules. PHB-free (stationary) cells of $R$. eutropha harbouring pBBR1MCS-2:: $\mathrm{P}_{\text {phac }}$ eyfp-b1934 could not be distinguished from eYfp-expressing cells (Fig. 5b). However, most cells of samples that had been taken after incubation under conditions permissive for PHB accumulation harboured PHB granules (stained with Nile red) that were almost exclusively located at the cell poles or in the 
(a) T18-

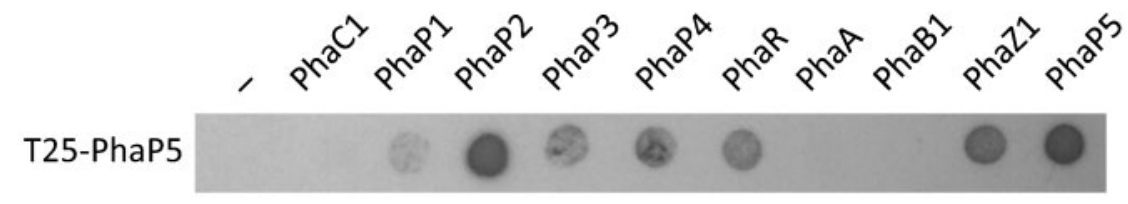

T25-
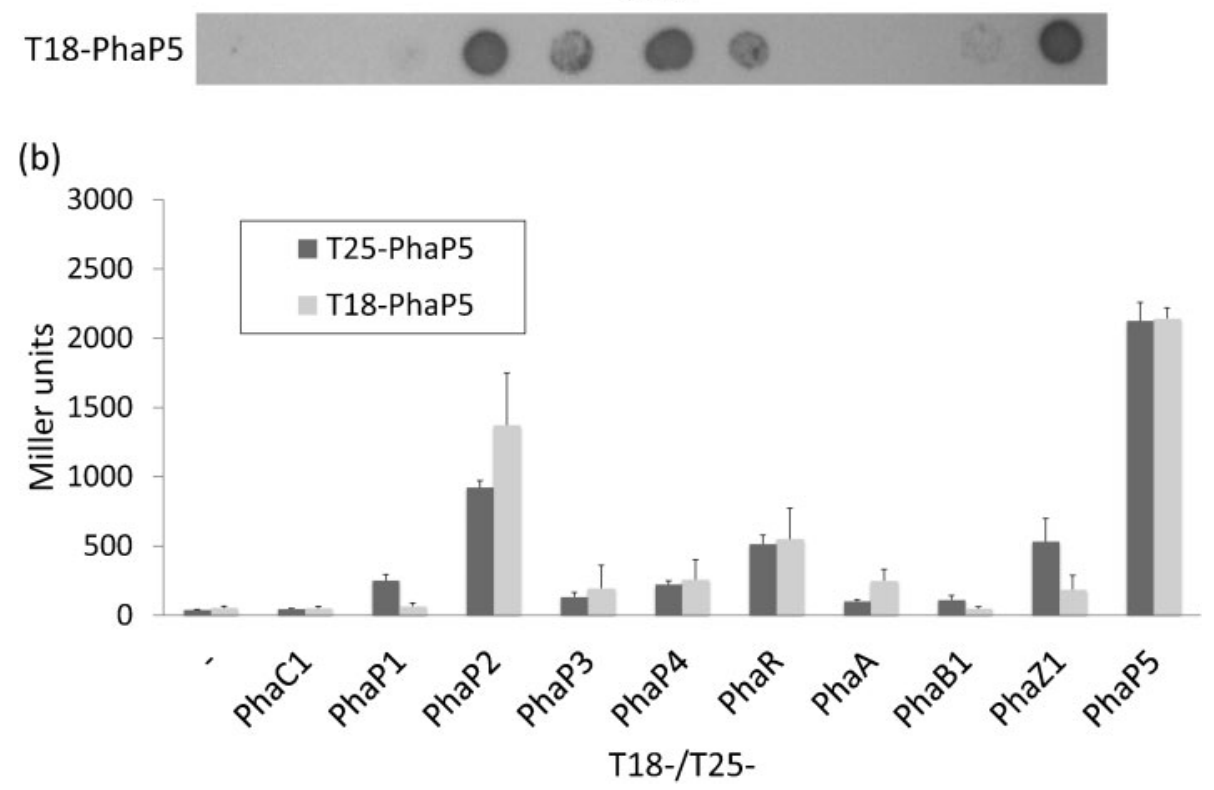

Fig. 4. $\mathrm{BACTH}$ analysis of $\mathrm{B} 1934$ (PhaP5) and known Pha proteins of $R$. eutropha. (a) Co-transformants of $E$. coli $\mathrm{BTH} 101$ expressing T18 and T25 fusions were spotted on M63-maltose-mineral salts agar, and plates were incubated at $30{ }^{\circ} \mathrm{C}$ for about 2 days at $30{ }^{\circ} \mathrm{C}$. (b) The efficiency of functional complementation was quantified by measuring $\beta$-galactosidase activities in suspensions of SDS/toluene-treated $E$. coli BTH101 cells harbouring the corresponding plasmids after growth at $30{ }^{\circ} \mathrm{C}$ for $16 \mathrm{~h}$. Values shown are the mean results from three independent cultures; error bars, SD. The Zip/Zip control yielded $2600 \mathrm{MU}$ in this experiment (results not shown). -, Empty vector.

area of future septum formation (Fig. $5 c$, d). The eYfp fluorescence colocalized with PHB granules and confirmed our assumption that the B1934 gene product is a PHB granule-associated phasin in vivo. At later stages of growth, PHB granules always colocalized with eYfp fluorescence (not shown). A chromosomal deletion mutant of B1934 was constructed for strains HF39 and H16 and investigated for PHB granule formation. However, the number, size and localization of PHB granules did not differ significantly from those of the respective wild-type (not shown). When an eYfp$\mathrm{PhaP} 2$ or an eYfp-PhaP4 fusion was expressed in R. eutropha, a colocalization of eYfp fluorescence and PHB granules was observed, confirming that $\mathrm{PhaP} 2$ and $\mathrm{PhaP} 4$ also represent true PGAPs (phasins) (Fig. 5e-h). However, formation of only cell pole-localized granules as for the eYfp-B1934 fusion was not observed for the PhaP2 and $\mathrm{PhaP} 4$ fusions.

\section{DISCUSSION}

In this study we used the bacterial adenylate cyclase-based two-hybrid (BACTH) system (Karimova et al., 2000b) to investigate interactions between proteins involved in $\mathrm{PHB}$ metabolism. The utility of the system was first tested for interactions between the class I model PHB synthase subunits ( $\mathrm{PhaCl}_{\text {Reu }}$ of $R$. eutropha) and the class IV model PHB synthase of $B$. megaterium $\left(\mathrm{PhaC}_{B m e g}\right.$ and $\left.\mathrm{PhaR}_{B m e g}\right)$ (McCool \& Cannon, 2001). Two-hybrid assays with $p h a C_{B m e g}$ and phaR $R_{\text {Bmeg }}$ resulted in the formation of blue colonies on indicator media (Fig. 1) and in levels of $\beta$ galactosidase activity that were three to five times higher than in the negative control. $\beta$-Galactosidase activity was significantly lower than the activity for the positive control (leucine zipper). However, one should consider that $\mathrm{PhaC}_{\text {Bmeg }}(40 \mathrm{kDa})$ and $\mathrm{PhaR}_{\text {Bmeg }}(22 \mathrm{kDa})$ are relatively large molecules that probably reduce the physical association of the two adenylate cyclase fragments by spatial hindrance. The positive control, the leucine zipper, is a domain of only $\sim 6 \mathrm{kDa}$, and is therefore unlikely to influence the association of adenylate cyclase fragments.

The two-hybrid assay with the R. eutropha class I PHB synthase $\left(64 \mathrm{kDa}, \mathrm{PhaC}_{\text {Reu }}\right)$ also resulted in the formation of blue colonies and in specific $\beta$-galactosidase activities that 
(a)

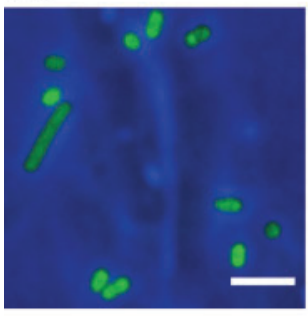

(e)

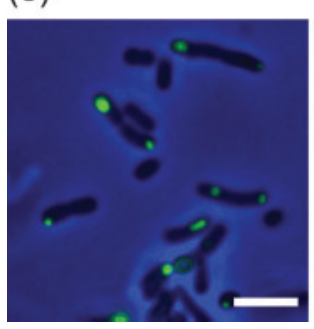

(b)

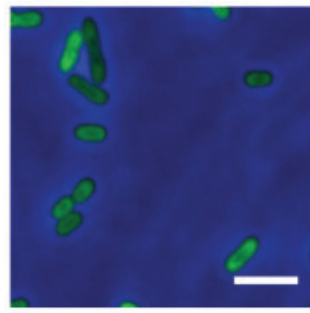

(f)

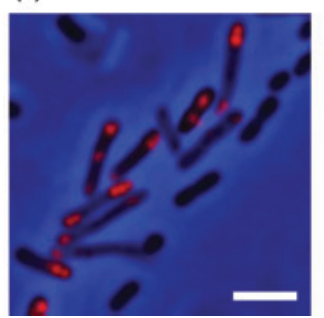

(c)

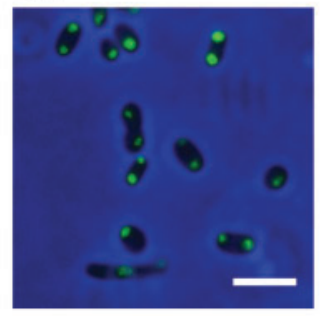

(g)

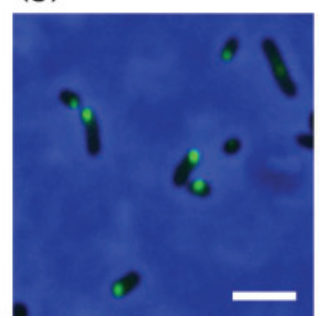

(d)

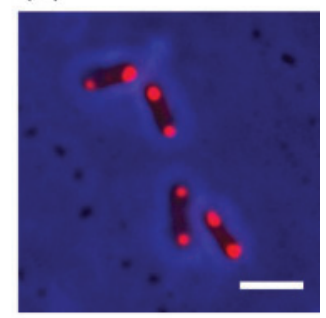

(h)

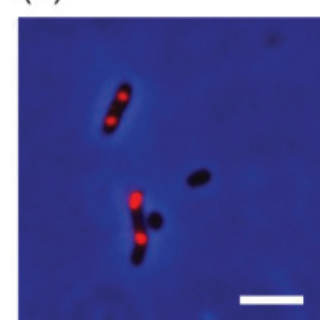

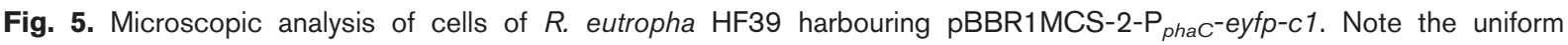
fluorescence of the cells, indicating soluble localization of free eYfp (a). R. eutropha HF39 harbouring pBBR1MCS-2-P phac- $^{-}$ eyfp-phaP5 (b-d): PHB-free cells (24 h NB seed culture) (b) were transferred to conditions permissive for PHB accumulation ( 0.1 vol. seed culture to fresh NB+0.2\% sodium gluconate) (c, d) and incubated at $30{ }^{\circ} \mathrm{C}$. Note the formation of eYfp foci predominantly at the cell periphery (cell poles) (c). The green foci colocalize with PHB granules, as indicated by staining with

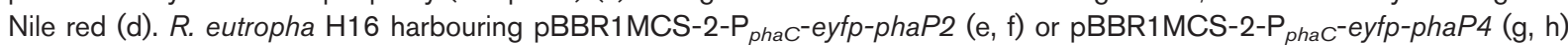
after transfer to conditions permissive for PHB accumulation. (e, g) eYfp fluorescence, $(f, h)$ Nile red fluorescence. Bars, $3 \mu \mathrm{m}$.

were about two to three times higher than background. Earlier studies by others have suggested that homodimerization of $\mathrm{PhaCl}_{R e u}$ is required for $\mathrm{PHB}$ synthesis in vitro (Stubbe et al., 2005; Wodzinska et al., 1996; Zhang et al., 2000, 2003). It is assumed that dimerization and binding of 3-hydroxybutyrate are the rate-limiting steps in the initiation of PHB synthesis by R. eutropha PHB synthase, and are responsible for the occurrence of a lag phase before maximal in vitro activity is obtained. The lower $\beta$ galactosidase activity in comparison with the two-hybrid assay of B. megaterium $\mathrm{PHB}$ synthase can be explained by homo-dimerization of the $\mathrm{T} 18-\mathrm{PhaC}_{\mathrm{Reu}}$ and $\mathrm{T} 25-\mathrm{PhaC}_{\text {Reu }}$ constructs, which reduces the probability of forming mixed dimers of $\mathrm{T} 18-\mathrm{PhaC}_{\text {Reu }}$ with $\mathrm{T} 25-\mathrm{PhaC}_{\text {Reu }}$. Only the mixed dimer will lead to reconstitution of adenylate cyclase activity and to formation of $\beta$-galactosidase activity. To our knowledge, the data confirm the postulated dimerization of PHB synthase in vivo for the first time.

A remarkable finding of the two-hybrid assays between nine known 'PHB players' (PhaA, PhaB1, PhaC1, PhaP1-4, $\mathrm{PhaR}$ and $\mathrm{PhaZ1}$ ) was the strong interaction between PhaP2 and other phasins, in particular with PhaP4 (Pötter et al., 2004). Previous work by Pötter and co-workers has shown that in vivo PhaP2 is apparently not detectably bound to isolated nPHB granules, although it is expressed in PHB-accumulating cells and has the capacity to bind to (artificial) PHB (Kuchta et al., 2007; Pötter et al., 2004, 2005; Pötter \& Steinbüchel, 2006). Srinivasan et al. (2002) detected PhaP2 by 2D PAGE of whole-cell extracts of fructose-induced cells, but at that time the R. eutropha genome sequence had not been published, and the protein was not identified as a phasin. In this study we confirmed that PhaP2 and PhaP4 clearly are attached to PHB granules in vivo and represent true phasins (Fig. 5). One could speculate that PhaP1 and/or other phasins control the access of PHB depolymerases such as PhaZ1 and/or other PGAPs to the PHB granule surface. This assumption is supported by the finding that $\mathrm{nPHB}$ granules isolated from R. eutropha $\triangle$ phaP1 mutants have a threefold higher $\mathrm{PHB}$ depolymerase activity than $\mathrm{nPHB}$ granules of the wild-type (unpublished results). Dennis and co-workers recently found a net-like structure on the surface of isolated PHB granules by atomic force microscopy that was reminiscent of a cytoskeleton (Dennis et al., 2003, 2008). It could be that PhaP2 and/or other PGAPs are part of this structure. This question was addressed by screening a genomic library for proteins interacting with PhaP2. The B1934 gene was identified in 24 clones with the strongest growth in the two-hybrid screening experiment. Analysis of published microarray data (Budde et al., 2010) indicates that B1934 is expressed under conditions permissive for PHB accumulation. The genes up- and downstream of B1934 on the chromosome are both transcribed in the opposite direction from B1934. Therefore, B1934 is not part of an operon. The eYfp-B1934 fusion protein was clearly identified as a PHB granule-bound protein (Fig. 5). We conclude that 
Table 3. Similarity of $R$. eutropha PhaP5 to other phasins

The identity values (above the diagonal of $100 \%$ values) and similarity values (below the diagonal) for the global alignment of PhaP5 (B1934 gene product) with other phasins are given.

\begin{tabular}{|lrrrrrrrr}
\hline \multirow{2}{*}{ Similarity } & \multicolumn{9}{c|}{ Identity } \\
\cline { 2 - 7 } & PhaP1 & PhaP3 & PhaP2 & PhaP4 & H16_B1934 & RALTA_B1632* & ApdA* & Mms16* $^{*}$ \\
\hline PhaP1 & $\mathbf{1 0 0 . 0} \%$ & $47.4 \%$ & $41.2 \%$ & $43.3 \%$ & $13.9 \%$ & $12.4 \%$ & $13.4 \%$ & $12.4 \%$ \\
PhaP3 & $62.4 \%$ & $\mathbf{1 0 0 . 0} \%$ & $37.6 \%$ & $38.7 \%$ & $17.0 \%$ & $14.9 \%$ & $16.0 \%$ & $14.4 \%$ \\
PhaP2 & $57.7 \%$ & $53.1 \%$ & $\mathbf{1 0 0 . 0} \%$ & $69.6 \%$ & $12.9 \%$ & $12.4 \%$ & $16.5 \%$ & $12.9 \%$ \\
PhaP4 & $60.8 \%$ & $55.2 \%$ & $78.9 \%$ & $\mathbf{1 0 0 . 0} \%$ & $13.4 \%$ & $11.9 \%$ & $16.0 \%$ & $12.9 \%$ \\
H16_B1934 & $22.2 \%$ & $25.2 \%$ & $20.6 \%$ & $19.6 \%$ & $\mathbf{1 0 0 . 0} \%$ & $84.5 \%$ & $41.8 \%$ & $54.1 \%$ \\
RALTA_B1632 & $21.1 \%$ & $23.7 \%$ & $20.1 \%$ & $18.6 \%$ & $87.6 \%$ & $\mathbf{1 0 0 . 0} \%$ & $37.6 \%$ & $47.9 \%$ \\
ApdA & $24.2 \%$ & $26.3 \%$ & $27.8 \%$ & $27.3 \%$ & $56.2 \%$ & $52.6 \%$ & $\mathbf{1 0 0 . 0} \%$ & $58.2 \%$ \\
Mms16 & $22.7 \%$ & $25.3 \%$ & $25.3 \%$ & $22.2 \%$ & $64.9 \%$ & $59.8 \%$ & $73.2 \%$ & $\mathbf{1 0 0 . 0} \%$ \\
& & & & & & & & \\
\hline
\end{tabular}

${ }^{\star}$ See text.

B1934 is a novel R. eutropha phasin protein, for which we propose the designation PhaP5. PhaP5 was able to interact with other phasins, in particular with $\mathrm{PhaP} 2$, but also with PhaR and PhaZ1. Our results show that some but not all proteins necessary for $\mathrm{PHB}$ synthesis have the ability to bind to each other, and indicate that the spatial organization of at least some of the proteins on the PHB granule surface is controlled. Our data also indicate that several phasins and other PGAPs constitute a complex ordered surface layer on $\mathrm{nPHB}$ granules that might result in the network-like structure on the PHB granule surface observed by Dennis et al. (2008). The deduced amino acid sequence of B1934 (15.7 kDa) revealed significant similarities to phasin proteins of species related to $R$. eutropha (65-90\% identity): Cupriavidus taiwanensis (RALTA_ B1632, $85 \%$ ), Rhodospirillum rubrum (ApdA, 42\%) and Magnetospirillum magneticum (Mms16, 54 \%) (Handrick et al., 2004). However, purified His-tagged B1934 protein did not increase the hydrolysis of nPHB granules by $R$. rubrum PhaZ1-like ApdA or Mms16 (unpublished data). The similarities of PhaP5 to $R$. eutropha phasins PhaP1 to PhaP4 were rather low ( $\leqslant 17 \%$ identity, Table 3$)$. In conclusion, PhaP5, together with RALTA_B1632, ApdA and Mms16, is a member of a new subgroup of phasin-like PGAPs in PHB-accumulating bacteria. The function of PhaP5 remains unclear: constitutive (over)expression of $\mathrm{PhaP} 5$ resulted in the formation of exclusively polar-localized PHB granules (Fig. 5). The same phenotype was observed for $R$. eutropha $\Delta$ phaP1-4: only polar-localized PHB granules were formed by this mutant (unpublished results). However, deletion of phaP5 alone showed no phenotype under the microscope. Apparently, a high concentration of PhaP5 (in relation to other phasins), obtained either by deletion of the other phasin genes or by overexpression of PhaP5, results in the formation of cell pole-localized PHB granules. The function of phasins PhaP2-PhaP4 remains unclear.

The detection of interactions between several classes of PGAPs is in agreement with the idea of a sophisticated 3D order of proteins with functions in $\mathrm{PHB}$ metabolism, and supports the idea of PHB granules being organelles (carbonosomes) (Jendrossek, 2009). At present, we do not know whether the identification of chemotaxis proteins and of other hypothetical proteins as potential interaction proteins for PhaP2 is significant or whether these clones are false-positives. Interestingly, a connection between $\mathrm{PHB}$ metabolism and motility and flagellin synthesis has been described (Raberg et al., 2008), and indicates that the twohybrid clones with chemotaxis genes may encode proteins that interact with PGAPs. It will be important to extend the two-hybrid screening assays to the remaining PHB granuleassociated proteins and to find out whether other PGAPs are still missing, as well as to confirm the associations identified between individual proteins in the PHBaccumulating strain itself, e.g. by Förster (fluorescence) resonance energy transfer (FRET) analysis.

\section{ACKNOWLEDGEMENTS}

This work was supported by the Deutsche Forschungsgemeinschaft. We thank D. Ladant, Institut Pasteur, Paris, France, for providing plasmid pUT18BC, and Pia Kaufmann for technical assistance in certain experiments.

\section{REFERENCES}

Abe, T., Kobayashi, T. \& Saito, T. (2005). Properties of a novel intracellular poly(3-hydroxybutyrate) depolymerase with high specific activity (PhaZd) in Wautersia eutropha H16. J Bacteriol 187, 6982-6990.

Budde, C. F., Mahan, A. E., Lu, J., Rha, C. \& Sinskey, A. J. (2010). Roles of multiple acetoacetyl coenzyme A reductases in polyhydroxybutyrate biosynthesis in Ralstonia eutropha H16. J Bacteriol 192, 5319-5328.

Dennis, D., Liebig, C., Holley, T., Thomas, K. S., Khosla, A., Wilson, D. \& Augustine, B. (2003). Preliminary analysis of polyhydroxyalkanoate inclusions using atomic force microscopy. FEMS Microbiol Lett 226, 113-119.

Dennis, D., Sein, V., Martinez, E. \& Augustine, B. (2008). PhaP is involved in the formation of a network on the surface of 
polyhydroxyalkanoate inclusions in Cupriavidus necator H16. J Bacteriol 190, 555-563.

Dove, S. L. \& Hochschild, A. (2001). Bacterial two-hybrid analysis of interactions between region 4 of the $\sigma^{70}$ subunit of RNA polymerase and the transcriptional regulators Rsd from Escherichia coli and AlgQ from Pseudomonas aeruginosa. J Bacteriol 183, 6413-6421.

Dove, S. L. \& Hochschild, A. (2004). A bacterial two-hybrid system based on transcription activation. Methods Mol Biol 261, 231-246.

Fields, S. \& Song, O. (1989). A novel genetic system to detect protein-protein interactions. Nature 340, 245-246.

Handrick, R., Reinhardt, S. \& Jendrossek, D. (2000). Mobilization of poly(3-hydroxybutyrate) in Ralstonia eutropha. J Bacteriol 182, 59165918.

Handrick, R., Reinhardt, S., Schultheiss, D., Reichart, T., Schüler, D., Jendrossek, V. \& Jendrossek, D. (2004). Unraveling the function of the Rhodospirillum rubrum activator of polyhydroxybutyrate (PHB) degradation: the activator is a PHB-granule-bound protein (phasin). J Bacteriol 186, 2466-2475.

Jendrossek, D. (2005). Fluorescence microscopical investigation of poly(3-hydroxybutyrate) granule formation in bacteria. Biomacromolecules 6, 598-603.

Jendrossek, D. (2009). Polyhydroxyalkanoate granules are complex subcellular organelles (carbonosomes). J Bacteriol 191, 3195-3202.

Jendrossek, D., Selchow, O. \& Hoppert, M. (2007). Poly(3-hydroxybutyrate) granules at the early stages of formation are localized close to the cytoplasmic membrane in Caryophanon latum. Appl Environ Microbiol 73, 586-593.

Karimova, G., Pidoux, J., Ullmann, A. \& Ladant, D. (1998). A bacterial two-hybrid system based on a reconstituted signal transduction pathway. Proc Natl Acad Sci U S A 95, 5752-5756.

Karimova, G., Ullmann, A. \& Ladant, D. (2000a). Bordetella pertussis adenylate cyclase toxin as a tool to analyze molecular interactions in a bacterial two-hybrid system. Int J Med Microbiol 290, 441-445.

Karimova, G., Ullmann, A. \& Ladant, D. (2000b). A bacterial twohybrid system that exploits a cAMP signaling cascade in Escherichia coli. Methods Enzymol 328, 59-73.

Karimova, G., Ullmann, A. \& Ladant, D. (2001). Protein-protein interaction between Bacillus stearothermophilus tyrosyl-tRNA synthetase subdomains revealed by a bacterial two-hybrid system. J Mol Microbiol Biotechnol 3, 73-82.

Karimova, G., Dautin, N. \& Ladant, D. (2005). Interaction network among Escherichia coli membrane proteins involved in cell division as revealed by bacterial two-hybrid analysis. J Bacteriol 187, 2233-2243.

Kidwell, J., Valentin, H. E. \& Dennis, D. (1995). Regulated expression of the Alcaligenes eutrophus pha biosynthesis genes in Escherichia coli. Appl Environ Microbiol 61, 1391-1398.

Kobayashi, T., Shiraki, M., Abe, T., Sugiyama, A. \& Saito, T. (2003). Purification and properties of an intracellular 3-hydroxybutyrateoligomer hydrolase (PhaZ2) in Ralstonia eutropha H16 and its identification as a novel intracellular poly(3-hydroxybutyrate) depolymerase. J Bacteriol 185, 3485-3490.

Kobayashi, T., Uchino, K., Abe, T., Yamazaki, Y. \& Saito, T. (2005). Novel intracellular 3-hydroxybutyrate-oligomer hydrolase in Wautersia eutropha H16. J Bacteriol 187, 5129-5135.

Kovach, M. E., Elzer, P. H., Hill, D. S., Robertson, G. T., Farris, M. A., Roop, R. M., II \& Peterson, K. M. (1995). Four new derivatives of the broad-host-range cloning vector pBBR1MCS, carrying different antibiotic-resistance cassettes. Gene 166, 175-176.

Kuchta, K., Chi, L., Fuchs, H., Pötter, M. \& Steinbüchel, A. (2007). Studies on the influence of phasins on accumulation and degradation of PHB and nanostructure of PHB granules in Ralstonia eutropha H16. Biomacromolecules 8, 657-662.

Lenz, O. \& Friedrich, B. (1998). A novel multicomponent regulatory system mediates $\mathrm{H}_{2}$ sensing in Alcaligenes eutrophus. Proc Natl Acad Sci U S A 95, 12474-12479.

McCool, G. J. \& Cannon, M. C. (1999). Polyhydroxyalkanoate inclusion body-associated proteins and coding region in Bacillus megaterium. J Bacteriol 181, 585-592.

McCool, G. J. \& Cannon, M. C. (2001). PhaC and PhaR are required for polyhydroxyalkanoic acid synthase activity in Bacillus megaterium. J Bacteriol 183, 4235-4243.

Pieper-Fürst, U., Madkour, M. H., Mayer, F. \& Steinbüchel, A. (1994). Purification and characterization of a 14-kilodalton protein that is bound to the surface of polyhydroxyalkanoic acid granules in Rhodococcus ruber. J Bacteriol 176, 4328-4337.

Pohlmann, A., Fricke, W. F., Reinecke, F., Kusian, B., Liesegang, H., Cramm, R., Eitinger, T., Ewering, C., Pötter, M. \& other authors (2006). Genome sequence of the bioplastic-producing "Knallgas" bacterium Ralstonia eutropha H16. Nat Biotechnol 24, 1257-1262.

Pötter, M. \& Steinbüchel, A. (2006). Biogenesis and structure of polyhydroxyalkanoate granules. In Inclusions in Prokaryotes, pp. 109-136. Edited by J. M. Shively. Berlin, Heidelberg: Springer Verlag.

Pötter, M., Madkour, M. H., Mayer, F. \& Steinbüchel, A. (2002). Regulation of phasin expression and polyhydroxyalkanoate (PHA) granule formation in Ralstonia eutropha H16. Microbiology 148, 2413-2426.

Pötter, M., Müller, H., Reinecke, F., Wieczorek, R., Fricke, F., Bowien, B., Friedrich, B. \& Steinbüchel, A. (2004). The complex structure of polyhydroxybutyrate (PHB) granules: four orthologous and paralogous phasins occur in Ralstonia eutropha. Microbiology 150, 2301-2311.

Pötter, M., Müller, H. \& Steinbüchel, A. (2005). Influence of homologous phasins (PhaP) on PHA accumulation and regulation of their expression by the transcriptional repressor PhaR in Ralstonia eutropha H16. Microbiology 151, 825-833.

Raberg, M., Reinecke, F., Reichelt, R., Malkus, U., König, S., Pötter, M., Fricke, W. F., Pohlmann, A., Voigt, B. \& other authors (2008). Ralstonia eutropha H16 flagellation changes according to nutrient supply and state of poly(3-hydroxybutyrate) accumulation. Appl Environ Microbiol 74, 4477-4490.

Rehm, B. H. (2003). Polyester synthases: natural catalysts for plastics. Biochem J 376, 15-33.

Rehm, B. H. (2006). Genetics and biochemistry of polyhydroxyalkanoate granule self-assembly: the key role of polyester synthases. Biotechnol Lett 28, 207-213.

Ruth, K., de Roo, G., Egli, T. \& Ren, Q. (2008). Identification of two acyl-CoA synthetases from Pseudomonas putida GPol: one is located at the surface of polyhydroxyalkanoates granules. Biomacromolecules 9, 1652-1659.

Saegusa, H., Shiraki, M., Kanai, C. \& Saito, T. (2001). Cloning of an intracellular poly[D(-)-3-hydroxybutyrate] depolymerase gene from Ralstonia eutropha $\mathrm{H} 16$ and characterization of the gene product. J Bacteriol 183, 94-100.

Simon, R., Priefer, U. \& Pühler, A. (1983). A broad hostrange mobilization system for in vivo genetic engineering: transposon mutagenesis in Gram-negative bacteria. Biotechnology 1, 794-791.

Srinivasan, S., Barnard, G. C. \& Gerngross, T. U. (2002). A novel high-cell-density protein expression system based on Ralstonia eutropha. Appl Environ Microbiol 68, 5925-5932. 
Srivastava, S., Urban, M. \& Friedrich, B. (1982). Mutagenesis of Alcaligenes eutrophus by insertion of the drug-resistance transposon Tn5. Arch Microbiol 131, 203-207.

Steinbüchel, A. \& Hein, S. (2001). Biochemical and molecular basis of microbial synthesis of polyhydroxyalkanoates in microorganisms. $A d v$ Biochem Eng Biotechnol 71, 81-123.

Stubbe, J. \& Tian, J. (2003). Polyhydroxyalkanoate (PHA) homeostasis: the role of PHA synthase. Nat Prod Rep 20, 445-457.

Stubbe, J., Tian, J., He, A., Sinskey, A. J., Lawrence, A. G. \& Liu, P. (2005). Nontemplate-dependent polymerization processes: polyhydroxyalkanoate synthases as a paradigm. Annu Rev Biochem 74, 433480 .

Sudesh, K., Abe, H. \& Doi, Y. (2000). Synthesis, structure and properties of polyhydroxyalkanoates: biological polymers. Prog Polym Sci 25, 1503-1555.

Thibodeau, S. A., Fang, R. \& Joung, J. K. (2004). High-throughput beta-galactosidase assay for bacterial cell-based reporter systems. Biotechniques 36, 410-415.

Uchino, K., Saito, T., Gebauer, B. \& Jendrossek, D. (2007). Isolated poly(3-hydroxybutyrate) (PHB) granules are complex bacterial organelles catalyzing formation of PHB from acetyl coenzyme A (CoA) and degradation of PHB to acetyl-CoA. J Bacteriol 189, 82508256.

Wang, Z. H., Ma, P., Chen, J., Zhang, J., Chen, C. B. \& Chen, G. O. (2011). A transferable heterogeneous two-hybrid system in Escherichia coli based on polyhydroxyalkanoates synthesis regulatory protein PhaR. Microb Cell Fact 10, 21.
Wodzinska, J., Snell, K. D., Rhomberg, A., Sinskey, A. J., Biemann, K. \& Stubbe, J. (1996). Polyhydroxybutyrate synthase: evidence for covalent catalysis. J Am Chem Soc 118, 6319-6320.

York, G. M., Junker, B. H., Stubbe, J. A. \& Sinskey, A. J. (2001a). Accumulation of the PhaP phasin of Ralstonia eutropha is dependent on production of polyhydroxybutyrate in cells. J Bacteriol 183, 42174226.

York, G. M., Stubbe, J. \& Sinskey, A. J. (2001b). New insight into the role of the PhaP phasin of Ralstonia eutropha in promoting synthesis of polyhydroxybutyrate. J Bacteriol 183, 2394-2397.

York, G. M., Stubbe, J. \& Sinskey, A. J. (2002). The Ralstonia eutropha PhaR protein couples synthesis of the PhaP phasin to the presence of polyhydroxybutyrate in cells and promotes polyhydroxybutyrate production. J Bacteriol 184, 59-66.

York, G. M., Lupberger, J., Tian, J., Lawrence, A. G., Stubbe, J. \& Sinskey, A. J. (2003). Ralstonia eutropha H16 encodes two and possibly three intracellular poly[D-(-)-3-hydroxybutyrate] depolymerase genes. J Bacteriol 185, 3788-3794.

Zhang, S., Yasuo, T., Lenz, R. W. \& Goodwin, S. (2000). Kinetic and mechanistic characterization of the polyhydroxybutyrate synthase from Ralstonia eutropha. Biomacromolecules 1, 244-251.

Zhang, S., Kolvek, S., Lenz, R. W. \& Goodwin, S. (2003). Mechanism of the polymerization reaction initiated and catalyzed by the polyhydroxybutyrate synthase of Ralstonia eutropha. Biomacromolecules 4, 504-509.

Edited by: V. Eijsink 